\title{
Loucos/as, pacientes, usuários/as, experientes: o estatuto dos sujeitos no contexto da reforma psiquiátrica brasileira
}

\author{
Crazies, patients, users, experienced: the statute of the subjects in the \\ context of the brazilian psychiatric reform
}

Ana Paula Müller de Andrade', Sônia Weidner Maluf²

\begin{abstract}
RESUMO Este artigo visa refletir sobre o estatuto dos sujeitos-usuários/as no contexto da reforma psiquiátrica brasileira. A partir de uma pesquisa etnográfica realizada em 2010 e 2011, com o objetivo de analisar criticamente o processo da reforma psiquiátrica brasileira, do ponto de vista de usuários/as dos serviços de saúde mental, problematiza-se a categoria 'usuário/a' e aponta-se para a complexidade e a relevância das experiências singulares e institucionais desses sujeitos na consolidação da política pública de saúde mental no Brasil. As análises indicam a necessidade de conferir um estatuto epistemológico ao saber produzido por tais sujeitos no contexto da reforma psiquiátrica brasileira.
\end{abstract}

PALAVRAS-CHAVE Política social. Desinstitucionalização. Sujeitos da pesquisa.

\begin{abstract}
This article aims to reflect about the statute of the subjects-users in the context of the Brazilian psychiatric reform. Based on an ethnographic research conducted in 2010 and 2011, which the objective of critically analyzing the process of the Brazilian psychiatric reform, from the point of view of the users of mental health services, the 'user' category is problematized and points out the complexity and the relevance of the singular and institutional experiences of these subjects in the consolidation of the public mental health policy in Brazil. The analysis indicates the need to confer an epistemological statute to the knowledge produced by such subjects in the context of the Brazilian psychiatric reform.
\end{abstract}

KEYWORDS Social policy. Deinstitutionalization. Research subjects.

\footnotetext{
1 Universidade Federal de Pelotas (UFPEL) - Pelotas (RS), Brasil.

psicopaulla@yahoo.com.br

2 Universidade Federal de Santa Catarina (UFSC) Florianópolis (RS), Brasil. sonia.maluf@ufsc.br
} 


\section{Introdução}

A reorientação da assistência psiquiátrica brasileira, consolidada com a aprovação da Política Nacional de Saúde Mental (PNSM), Lei $\mathrm{n}^{\circ} 10.216 / 2001$, teve como eixo norteador a garantia de dignidade e de liberdade para pessoas acometidas por algum tipo de sofrimento psíquico. Diante de críticas e denúncias de diferentes atores sociais sobre as condições desumanas e pouco terapêuticas dispensadas aos considerados doentes mentais nos hospitais psiquiátricos brasileiros, bem como do reconhecimento de experiências de transformação da assistência psiquiátrica em outros países, como França, Inglaterra, Estados Unidos e Itália, o processo de reforma psiquiátrica ganhou força no Brasil.

A partir da aprovação da PNSM, os princípios da reforma psiquiátrica têm orientado, na sua vertente assistencial, a criação de uma rede de serviços de saúde mental abertos, de base comunitária, que, articulados com outros setores, visam substituir os leitos em hospitais psiquiátricos e garantir a formulação de estratégias terapêuticas singulares para os sujeitos. Como apontado por Wetzel (2005), tais serviços vêm se concretizando de forma heterogênea em todo Brasil.

A participação de diferentes atores - movimentos sociais, trabalhadores, familiares, artistas e pessoas incluídas na categoria de usuários do sistema de saúde - no processo de formulação e consolidação da política pública de saúde mental no País promoveu mudanças importantes na assistência psiquiátrica ofertada e tem instituído outro lugar social para a loucura e para as pessoas consideradas loucas, entendidas aqui como aquelas que têm o encargo simbólico de corporificar a loucura (PELBART, 1990).

A exemplo da substituição, no Novo Código Civil Brasileiro (2002), da expressão 'loucos de todo gênero' por 'os que, por enfermidade ou deficiência mental, não tiverem o necessário discernimento para a prática desses atos', para denominar as pessoas consideradas incapazes para os atos da vida civil, outras mudanças têm sido instituídas a fim de atender a complexidade de centrar a assistência psiquiátrica no sujeito que sofre e não na suposta doença que o acomete. Além dessa substituição, no contexto dos serviços de saúde mental criados a partir da aprovação da PNSM, tais pessoas passaram a ser denominadas como 'usuárias/os', em substituição às expressões 'doente mental', 'louco' ou 'cliente', consideradas inadequadas frente ao seu protagonismo (AMARANTE, 1995).

A fim de discutir o estatuto conferido aos sujeitos-usuários/as no contexto da reforma psiquiátrica brasileira, destacam-se aqui os dados de uma pesquisa etnográfica, que teve o objetivo de analisar criticamente o processo da reforma psiquiátrica brasileira do ponto de vista de usuários/as dos serviços de saúde mental, cujos resultados indicaram a necessidade de conferir um estatuto epistemológico ao saber produzido por esses sujeitos.

\section{Metodologia}

A pesquisa foi realizada nas cidades de Joinville (SC) e Barbacena (MG), nos anos de 2010 e 2011. A opção pela abordagem qualitativa e etnográfica justificou-se pela possibilidade de enfatizar os diferentes discursos e práticas presentes no contexto investigado, e de articular os dados empíricos com a teoria, colocando-os em diálogo.

Durante nove meses, foram feitas observações participantes, entrevistas semiestruturadas (realizadas na fase inicial do trabalho de campo) e conversas ordinárias e extraordinárias, com usuários/as dos serviços de saúde mental. Os dados foram registrados em diário de campo e as entrevistas gravadas e transcritas. Os nomes de pessoas utilizados neste texto são fictícios.

A escolha dos usuários/as dos serviços de saúde mental substitutivos ao hospital 
psiquiátrico deu-se pelo entendimento de que o ponto de vista e as experiências desses sujeitos sobre o processo da reforma psiquiátrica brasileira trariam contribuições importantes para a análise a ser realizada. Do conjunto dos sujeitos que compuseram a pesquisa, foram selecionados dois para o desenvolvimento do argumento apresentado neste trabalho.

A inserção etnográfica se deu em diferentes 'planos' (MALUF, 2011), entre eles, o plano institucional (conferências municipais de saúde, serviços de saúde mental governamentais e não governamentais) e o plano das experiências singulares dos sujeitos (rotinas ordinárias e extraordinárias, percursos pela cidade, visitas domiciliares, idas a feiras e restaurantes, entre outros), que foram articulados na construção da análise realizada.

O trabalho de campo não foi realizado com um grupo ou em um local específico, mas com as pessoas que participavam de atividades ligadas ao chamado campo da saúde mental. Os/as sujeitos da pesquisa eram homens e mulheres adultos, em sua maioria, pertencente às classes populares urbanas, que tinham em comum o fato de frequentarem ou já terem frequentado serviços de saúde mental e fazerem ou já terem feito uso de psicofármacos. Nas duas cidades, foi solicitado, aos primeiros interlocutores, que indicassem outras pessoas que pudessem participar, tal como sugerido por Bott (1976), e, assim, foi composto o grupo de sujeitos investigados. A pesquisa foi aprovada em Comitê de Ética.

\section{Resultados e discussão}

\section{Usuários/as entre aspas}

No texto da PNSM, as pessoas acometidas por algum tipo de sofrimento, aflição ou perturbação (DUARTE, 1994) são denominadas 'pessoas portadoras de transtornos mentais'.
Tal expressão é usada no texto da política para denominar os indivíduos que deverão ter garantidos o direito a tratamento em serviço aberto, sem qualquer forma de discriminação quanto à raça, à cor, ao sexo, à orientação sexual, à religião, à opção política, à nacionalidade, à idade, à família, a recursos econômicos e/ou ao grau de gravidade ou tempo de evolução de seu transtorno, ou a qualquer outra.

No senso comum, tais pessoas são reconhecidas através de expressões como 'pacientes', ‘doentes mentais', 'loucas/ os', 'birutas', 'doidas', 'tantãs', entre tantas outras. Tais expressões se relacionam com o contexto social, cultural, ideológico, teórico em que aparecem e, em geral, refletem a maneira como tais pessoas são percebidas pelas demais.

No contexto da reforma psiquiátrica brasileira, são comumente denominadas como 'usuárias'. Tal expressão encontra respaldo no fato d'elas terem sido protagonistas nos processos de construção e consolidação do Sistema Único de Saúde (SUS), bem como de usarem os serviços que dele fazem parte. Entretanto, além dos diferentes usos que tais sujeitos fazem dos e nos serviços, cabe salientar a sua participação em outros espaços de sustentação e execução da PNSM, tais como os conselhos de saúde e outros fóruns em que a política é gestada, como mostra, por exemplo, o trabalho de Silveira, Brante e van Stralen (2014)

O reconhecimento da importância de tais pessoas no processo da reforma psiquiátrica brasileira pode ser percebido, por exemplo, na Marcha dos Usuários pela Reforma Psiquiátrica Antimanicomial, realizada em setembro de 2009, na cidade de Brasília (DF). A marcha teve como objetivo mobilizar a sociedade civil para reivindicar, junto ao governo federal, a realização da IV Conferência Nacional de Saúde Mental. Para tanto, foi organizada com apoio do Conselho Federal de Psicologia e da Rede Internúcleos da Luta Antimanicomial (Renila). A 
chamada principal era 'Marcha dos Usuários pela Reforma Psiquiátrica Antimanicomial! Brasília vai ouvir nossa voz', em uma clara referência de que os/as usuários/as deveriam ser escutados (SILVEIRA; BRANTE; VAN STRALEN, 2014).

Como resultado de tal mobilização, a IV Conferência Nacional de Saúde Mental foi realizada, no ano de 2010, com a participação de outros setores além da saúde, o que agregou à tal conferência um caráter intersetorial. Com isso, a paridade na representação foi remodelada, ficando $70 \%$ para o setor saúde (dos quais, $50 \%$ para usuários, $25 \%$ para gestores e $25 \%$ para trabalhadores) e $30 \%$ para a intersetorialidade (na qual se destacaram os setores de educação, trabalho e cultura, entre outros), o que buscou garantir a ampla participação dos/as usuários/as (BRASIL, 2010).

Para Amarante (1995), a expressão 'usuário' surge no interior do processo de reforma psiquiátrica brasileira e pretende substituir as expressões utilizadas até então. Contudo, para o autor, em pouco tempo se percebe que a expressão 'usuário' remete às mesmas consequências anteriores. Então, ele não sugere outra expressão capaz de substituí-la, mas demonstra, em Torre e Amarante (2001, P. 79), como houve, no processo da reforma psiquiátrica, uma "transformação do lugar do louco como ator social, como sujeito político".

Cecílio et al. (2014) argumentam sobre um agir leigo no âmbito da saúde e alegam que os usuários são sujeitos cognoscentes, cognoscíveis e produtores de seus sistemas de saúde. O conceito de leigo é pensado pelos autores como um saber advindo das experiências sociais e que não está necessariamente referenciado a uma área do conhecimento ou saber especializado.

Já Carvalho (2014) aponta que o uso da expressão ‘usuário’ em substituição a 'paciente', usada por profissionais e militantes da reforma psiquiátrica, remete ao uso dos serviços de saúde por uma determinada população e pretende superar a reificação e a redução de tais pessoas a uma condição patologizável. Segundo o autor, ainda assim, com frequência alguns desses profissionais se referem a elas como pacientes.

Uma problematização desta expressão também é apresentada na 'Carta de direitos e deveres dos usuários e familiares dos serviços de saúde mental', que, entre outras coisas, descreve:

Utilizamos a expressão 'usuário', assim como se usa a expressão 'técnicos', para designar situações específicas. Na verdade, nós, usuários entre aspas, somos pessoas, seres humanos totais integrais, acima das condições circunstanciais dos Serviços de Saúde Mental. (CARTA DE DIREITOS E DEVERES DOS USUÁRIOS E FAMILIARES DOS SERVIÇOS DE SAÚDE MENTAL, 1993, P. 1).

Ao apontar para o fato de que as expressões 'usuário' e ‘técnico' designam situações específicas, o texto produzido na carta faz pensar no caráter irredutível da complexidade e da integralidade das experiências dos sujeitos a qualquer tipo de denominação, bem como nas possíveis limitações que a expressão 'usuários/as' possa conter.

No processo de reflexão e análise dos dados da pesquisa realizada, optou-se pela expressão 'experientes' para fazer referência a essas pessoas. O objetivo dessa opção foi destacar a importância que as experiências singulares e institucionais mostravam ter na constituição de práticas e relações nos serviços de saúde mental e também fora deles, bem como no processo da reforma psiquiátrica de modo mais amplo. Além disso, tal opção possibilitou refletir densa e criticamente sobre a expressão 'usuário/as'.

A ideia do uso da expressão 'experientes' emergiu da discussão proposta por Maluf (2010) ao propor uma abordagem antropológica do contexto das políticas de saúde mental no Brasil. A autora, na construção de seu argumento, coloca a palavra usuário entre aspas e discute a relevância da experiência social destas pessoas para o contexto da política pública de saúde mental no Brasil. Por experiência social, designa 
a dimensão da vivência e produção de saberes e discursos por parte daquelas que são justamente o 'público-alvo' das políticas públicas e da atuação de profissionais e agentes de saúde [...]. (MALUF, 2010, P. 40).

Outro aporte teórico para a escolha da expressão 'experientes' adveio das considerações de Coleman (2004). O autor argumenta sobre a importância da experiência pessoal na trajetória de recuperação de pessoas com algum tipo de mal-estar mental. Para ele, as experiências das pessoas que são acometidas por algum mal-estar e também daquelas que com elas convivem e trabalham devem ser consideradas no processo de recuperação do bem-estar perdido. Estas diferentes proximidades com a experiência do mal-estar, próprio ou de outrem, são definidas pelo autor a partir de diferentes designações para as pessoas envolvidas: 'expert por experiência' (l'esperto per esperienza), ou seja, a pessoa que experimenta algum tipo de incômodo psíquico e 'expert por profissão' (l'esperto per professione), o profissional que a acompanha.

É possível, ainda, acrescentar às denominações de Coleman (2004) a expressão 'expert por convivência', para denominar as pessoas que convivem no âmbito privado com a pessoa que tem algum mal-estar, e que são reconhecidas e denominadas comumente no contexto dos serviços de saúde mental como familiares.

Considerar a experiência como uma categoria importante para a análise desenvolvida neste artigo significa admitir que essas experiências são produzidas pelos sujeitos em contextos socioculturais e históricos específicos, e não devem ser naturalizadas ou mesmo ontologizadas. Como propõe Scott (1999), é preciso analisar a natureza discursiva da experiência e sua construção política. Para a autora, os

[...] sujeitos são constituídos discursivamente, a experiência é um evento linguístico (não acontece fora de significados estabelecidos), mas não está confinada a uma ordem fixa de significados. Já que o discurso é, por definição, compartilhado, a experiência é coletiva assim como individual. Experiência é uma história do sujeito. A linguagem é o local onde a história é encenada. (SCOTT, 1999, P. 42).

Nesse sentido, a interlocução com os sujeitos da pesquisa permitiu considerar o modo como as pessoas falavam de si no contexto da reforma psiquiátrica brasileira, entendendo que não falavam apenas de si nem somente para outrem, mas também para si, como um modo de constituir tanto suas experiências quanto a si mesmos. Nas análises, buscou-se produzir um conhecimento que conjugasse as dimensões coletiva e individual de tais experiências, tal como proposto por Scott (1999).

\section{Experientes: um outro estatuto para os sujeitos}

Os dados analisados, advindos da interlocução com usuários/as dos serviços de saúde mental sobre o processo da reforma psiquiátrica brasileira, permitiram, entre outras coisas, perceber que existia uma tensão entre o plano institucional da reforma psiquiátrica e aquele em que se constituem as experiências singulares e institucionais dos sujeitos que o compõem.

Além disso, o reconhecimento de tais planos diferenciados, bem como do tensionamento entre eles, indicou que, nos processos de constituição dos sujeitos nas relações estabelecidas entre os distintos atores da reforma psiquiátrica, operam diferentes lógicas e interpretações sobre os processos de adoecimento e suas terapêuticas. Assim, se por um lado podemos indicar que a interpretação biomédica é hegemônica do ponto de vista dos discursos e práticas das políticas públicas e dos serviços de saúde, por outro, do ponto de vista dos sujeitos sociais envolvidos, também é possível 
afirmar que outras interpretações, sobretudo aquelas baseadas no modelo físico-moral dos nervos (DUARTE, 1988), estão presentes em suas práticas e discursos.

A partir dos diálogos estabelecidos com dois interlocutores da pesquisa, evidenciam-se alguns elementos importantes para a discussão sobre a articulação entre diferentes modelos interpretativos, práticas e discursos que conformam as experiências no contexto da reforma psiquiátrica brasileira, especialmente naqueles aspectos relacionados à prescrição e ao uso de psicofármacos, e aos diferentes agenciamentos dos sujeitos em relação à medicação. Daniel, um dos interlocutores da pesquisa, narra, em uma das conversas, sua experiência com os medicamentos:

Eu gostei muito da psicofarmacologia porque dá pra mim... agora, quando tinha o médico do convênio, eu falava com ele, eu dialogava com ele. Com o médico do SUS, não dá, é muito rápido. Então, até a gente esperar, leva aquele tempo, aquela angústia, aquela agonia... Então, como eu tenho conhecimento de psicofarmacologia, eu faço, eu mesmo, a retirada... [Pergunto:] 'Como assim, tu mesmo faz a retirada?' [Ele responde:] 'É assim, ó: o vapakene, depakene é para transtorno de humor, é para afetividade. Então, é assim... [pausa breve] Então, eu me dei mal... [pausa breve] Então, eu tiro um a menos, eu boto um a mais [...] porque o médico conhece eu, né?! Mas ele não conhece bem meu organismo [pausa breve] porque eu sei que o remédio pros nervos, ele não cura, né?! O médico sabe os sintomas, mas aí, ele dá, ele dá e ele vai saber, ele conhece pelos efeitos colaterais. Se for dar muito efeito colateral, ele tira e passa pro outro. Eu sei, é assim o esquema que funciona. Isso aí, eu sei. Mas, aí, eu fiz ali. Então, agora eu tô tomando a ziprazidona. Eu fiz uma experiência hoje de manhã mesmo, eu tava há uns dez dias, eu tava meio assim... irritado... Aí, eu fiz assim: de manhã, eu tirei um valpakene... [...]'. (fragmento do Diário de Campo)
Cumpre dizer que Daniel era um homem que pertencia às classes populares, tinha aproximadamente 40 anos, era separado, pai de 2 filhos e com uma história de longas e sucessivas internações psiquiátricas. Considerando sua experiência com a terapêutica medicamentosa, ele entendia que o médico o conhecia, mas não conhecia seu organismo, o que também significava dizer que o médico o conhecia, mas não o suficiente para entender o seu organismo tanto quanto ele, como indica em seu relato.

Além disso, para ele, o médico reconhecia aquilo que compunha a interpretação biomédica da sua experiência: sintomas e efeitos colaterais. Já o que Daniel reconhecia era que, manejando os remédios e articulando seus conhecimentos, inclusive, o de psicofarmacologia, podia fazer tentativas de ajuste medicamentoso tal como faz o médico, que "conhece pelos efeitos colaterais. Se for dar muito efeito colateral, ele tira e passa pro outro".

Não se trata, aqui, de fazer um julgamento sobre a terapêutica adotada nos serviços de saúde mental, ainda que isto seja muito pertinente, mas apontar como diferentes experiências conformam diferentes usos e discursos em torno dessas terapêuticas, incluindo as medicamentosas. Também não significa dizer que uma experiência tem mais valor do que outra ou, então, que o profissional e/ou os sujeitos-alvo de tal terapêutica estão mais, ou menos, autorizados a falar sobre elas. A intenção é mostrar que tanto a experiência de Daniel quanto a do médico ao qual ele se referia na conversa são atravessadas, uma pela outra, e se constituem em relações de poder, de reciprocidade e, também, de circularidade.

Como foi percebido no desenvolvimento da pesquisa, é no emaranhado das relações de poder (FOUCAULT, 2009), que fazem parte do processo da reforma psiquiátrica, que é possível reconhecer a emergência de experiências e de sujeitos capazes de estabelecer outras possibilidades de relacionamento. Assim, não se trata de reificar um 
lugar comum e estático reservado aos usuários/as e/ou aos profissionais que com eles convivem, mas de considerar que o tensionamento de diferentes interpretações acerca das experiências de sofrimento psíquico produz e é produzido por conhecimentos e configurações de valores que precisam ser reconhecidos. Segundo Cardoso, Oliveira e Piani (2016, P. 97),

todos os atores envolvidos no processo de cuidado criam condições, estratégias e espaços de participação, possibilitando a discussão e a problematização de todas as questões que envolvem o contexto e o cotidiano implicados no cuidado.

Nesse sentido, o estatuto do sujeito que predomina nas relações estabelecidas nesse contexto é dado prioritariamente pelo discurso biomédico. É o discurso biomédico que determina, por exemplo, as categorias a partir das quais esses sujeitos serão definidos ou classificados: usuários/as, profissionais, familiares etc. E, particularmente em relação aos usuários/as, essa definição é dada, sobretudo, através da prescrição diagnóstica. Contudo, percebe-se que essas são, também, categorias precárias, uma vez que um sujeito pode ser usuário, familiar e, em alguns casos, profissional da saúde mental, ao mesmo tempo. Tais classificações podem ser conjugadas de várias maneiras. Quanto aos usuários/as, alguns conseguem romper com a prescrição dada pelo diagnóstico, e até fazer deslocamentos, ainda que precários, a partir de alguns requisitos, como saber falar em público, pertencer a uma classe social mais favorecida economicamente e compartilhar um conjunto de expressões/palavras tidas como 'científicas', tal como a nomenclatura médica, por exemplo.

Dessa maneira, seria possível pensar que todas as pessoas, em suas diferentes posições nesse contexto, são experientes, visto que, cada uma à sua maneira e em circunstâncias específicas, experimenta-se em suas relações com e no mundo. Como sugeriu Coleman (2004), uma é expert por profissão; a outra, expert por experiência. Entretanto, entende-se que tais experiências são históricas e dotadas de sentidos assim situados. Tal como se percebe no relato de Daniel, sua experiência se constituiu a partir da articulação dessas diferentes condições e da sua aproximação com o modelo de interpretação biomédica, porque ele já observou e percebeu "como o esquema funciona". Sendo assim, sua experiência é, como sugeriu Scott (1999, P. 48), "ao mesmo tempo, já uma interpretação e algo que precisa de interpretação". Interessa, aqui, analisar como o que Coleman define como expert 'por experiência' - em especial, o chamado usuário do sistema de saúde, diagnosticado e em tratamento - constitui seu próprio saber e suas próprias teorias sobre essa experiência e sobre as relações que se estabelecem entre eles, profissionais, instituições e, mesmo entre eles e as terapêuticas utilizadas.

Outro diálogo ocorrido durante o trabalho de campo também ajuda nessa discussão. $\mathrm{Na}$ conversa com Mateus, outro interlocutor, homem jovem, de aproximadamente 25 anos, negro, pertencente às classes populares, ele contou sobre sua primeira internação em um hospital psiquiátrico e falou das lembranças ruins que tinha daquele período. Ele disse que já havia percorrido diversos serviços de saúde mental depois que saiu do hospital psiquiátrico, e já tinha feito uso de medicamentos de todos os tipos e terapêuticas diversas (incluindo as de ordem religiosa), até que, em um determinado momento de sua vida, uma psiquiatra lhe prescreveu um medicamento que fez com que se sentisse melhor. Ele não sabia dizer exatamente o que a psiquiatra tinha avaliado, tampouco a que saber específico tinha recorrido para tal prescrição. O que sabia era que ela havia lhe feito uma prescrição medicamentosa que havia aliviado seus sintomas.

Diante de suas experiências, Mateus entendia que a prescrição e a gestão do uso 
dos medicamentos era uma experimentação, tanto para os/as usuários/as como para os/ as prescritores/as. Nesse sentido, ambos estariam no mesmo patamar de experimentação, distintos apenas na especificidade e na hierarquia de seus saberes. Ele disse:

O médico ainda tem um poder muito grande, e eu acho que, em psiquiatria, por mais que ele saiba, ele também não sabe muita coisa. Eles fazem um laboratório com a gente, eles vão dando esse remédio, esse remédio... Ah, se funciona, tudo bem! Se não, eles tentam...

$\mathrm{O}$ argumento de Mateus indica uma problematização do saber psiquiátrico (FOUCAULT, 1997). Ele reconhece que 'o médico tem um poder muito grande', mesmo que esteja no mesmo patamar de experimentação que os/as usuários/as, uma vez que 'ele também não sabe muita coisa'. Seu argumento também aponta que, tal como propôs Foucault (1997), o saber psiquiátrico, ao instituir, em determinado momento histórico, a doença mental como seu objeto, pressupôs que ela deveria ser submetida a um tratamento que lhe correspondesse. Entretanto, para Mateus, tanto o saber psiquiátrico quanto a terapêutica medicamentosa se ocupam de objetos imprecisos e, por isso, demandam um exercício de experimentação. Neste sentido, usuário/a e profissional partilham experiências e experimentações, a partir de diferentes discursos, modelos interpretativos e em processos relacionais.

Como discutido até aqui, esses processos são constituídos em relações de poder, e é no contexto destas relações de poder que a experiência de sujeitos acometidos por algum tipo de sofrimento, aflição ou perturbação tende a ser objetivada e naturalizada como um evento estritamente biológico. Compreender essa dimensão é importante para admitir que a complexidade e a singularidade das experiências sejam contempladas no âmbito da política pública de saúde mental, especialmente em sua execução nas práticas assistenciais. Caso contrário, a descoberta dos psicofármacos, por exemplo, poderá determinar outra relação dos/as usuários/as com as instituições (possibilitando, de acordo com algumas interpretações, a desospitalização), mas não desencadeará mudanças nessas relações de poder, uma vez que o 'louco' seguirá sendo o 'louco' e suas experiências acabarão sempre sendo interpretadas a partir de uma razão psicopatológica, como apontou Basaglia (2005).

A discussão sobre o uso de psicofármacos é complexa, tensa e intensa, e sua análise ultrapassa os limites e objetivos deste artigo. Ainda assim, destaca-se que a terapêutica medicamentosa esteve presente de forma significativa no contexto investigado e, tal como mostram os relatos apresentados, ela não está reduzida à prescrição, à gestão e aos seus usos, mas também a questões de poder e controle mais amplas.

Mesmo considerando a importância dos psicofármacos como uma das terapêuticas possíveis no contexto da assistência psiquiátrica, a manutenção de sua centralidade no contexto da reforma psiquiátrica brasileira precisa, no mínimo, ser relativizada. Outrossim, parece interessante pensar em como uma política pública, que pretende apostar no sujeito e em sua autodeterminação (ou 'autonomia', tal como aparece nos discursos em torno dos processos de desinstitucionalização ou desospitalização), na subjetividade e na palavra, ainda investe subjetiva e materialmente nos psicofármacos, representantes de um regime eminentemente farmacológico, objetivante e redutor da experiência social e subjetiva dos sujeitos.

Uma das possibilidades de reflexão sobre esse aspecto encontra respaldo em Foucault (2009). Ao apresentar uma história das práticas coercitivas como dimensão política, o autor mostra que as mesmas, agenciadas por uma micropolítica constituída na maquinaria institucional, além de produzirem relações de submissão, fabricam corpos dóceis e corpos/máquinas que interessam 
aos jogos de poder da sociedade, tal qual se inscreve no ponto de vista da economia e da política. Assim, o poder não exerceria apenas a função de repressão e exclusão, pois seria muito frágil. O poder é dotado de uma positividade que, ao contrário de impedir o saber, o produz, a ponto de transformar aquilo que seria um 'movimento de controle-repressão' em 'controle-estimulação' (FOUCAULT, 2009). Assim, sendo o sujeito o alvo da manifestação desses micropoderes, é possível observar que a terapêutica medicamentosa, para além de um aparente cuidado médico, remete às diferentes faces do poder e do controle.

No contexto investigado, foi possível perceber que, de alguma maneira, em meio às transformações da assistência psiquiátrica no Brasil, se deixou de controlar os loucos através do aparato asilar, na sua estrutura física - ou seja, entre os muros dos hospitais psiquiátricos - e se passou a controlar a 'loucura' (ou, do ponto de vista biomédico, a doença) através do imperativo da terapêutica medicamentosa.

Contudo, as análises apontam para a relevância das experiências desses sujeitos-usuários/as dos serviços e da biomedicina, denominados aqui 'experientes'. Tal como foi percebido, é através destas experiências que vão se constituindo estratégias capazes de subverter e/ou possibilitar outras aproximações com o sofrimento e as aflições, e suas possíveis terapêuticas. Considerar com seriedade tais experiências permite ampliar a compreensão das relações de poder presentes no contexto da reforma psiquiátrica brasileira e conferir um estatuto epistemológico ao saber produzido pelos sujeitos.

Reconhecem-se, também, outras experiências que auxiliam nessa discussão, algumas adquirindo uma dimensão mais coletiva e mesmo institucionalizada, como a do Movimento dos Ouvidores de Vozes (Hearing Voices Network). Ao apoiar-se na experiência dos sujeitos, o movimento busca romper com a hegemonia do modelo biomédico e construir estratégias de enfrentamento à experiência de ouvir vozes. Tal como apontam Romme et al. (2010), o movimento dos ouvidores de vozes surgiu na Holanda, em meados dos anos 1990. Nos anos seguintes, se desenvolveu no Reino Unido, onde o movimento é muito forte, e também na Alemanha, na Itália e em outros países europeus. Tal movimento realiza encontros regionais, nacionais e internacionais, e baseia-se, sobretudo, na formação de grupos de ajuda mútua, coordenados tanto por profissionais como por ouvidores de vozes.

Segundo Cardano e Lepori (2013), um ponto central para os ouvidores de vozes é o fato de rejeitarem a etiqueta de 'loucos', de 'esquizofrênicos' e proporem para si mesmos serem 'ouvidores de vozes', ou seja, pessoas dotadas de certa capacidade e portadoras de uma experiência singular, a de ouvir vozes. Tais grupos tendem a valorizar, desta forma, as experiências e os conhecimentos dos sujeitos, seja em suas experiências nas redes de sociabilidade individuais, seja na rede institucional, constituída por um movimento internacional que os agrega.

Nesse sentido, o movimento confere visibilidade aos sujeitos, legitimidade às suas interpretações sobre a experiência de ouvir vozes e, de certa forma, impacta a política pública nos países em que se desenvolve. Ao considerar as estratégias destes sujeitos para enfrentar a experiência de ouvir vozes, o movimento propõe que os ouvidores devem reconhecer/aceitar suas experiências com as vozes, buscar estratégias para lidar com elas, tentando compreender seus significados e suas origens. Muitos sujeitos ouvidores de vozes recorrem aos cuidados biomédicos, fazem uso de psicofármacos; outros não, tal como apontam Romme et al. (2010), Cardano e Lepori (2013) e Coleman (2004).

No Brasil, os estudos de Barros e Serpa Jr. (2014) e Muñoz (2009) também apontam para a importância de considerar a experiência vivida pelos sujeitos que ouvem vozes. A partir de pesquisas inspiradas na experiência holandesa de grupos de ouvidores de vozes, 
os/as autores/as destacam, entre outros aspectos, a importância de

[...] dar voz aos que ouvem vozes como uma estratégia clínica que não está desarticulada da política, pois tem no horizonte o objetivo de disponibilizar um saber-fazer com as vozes para todos que dele precisarem. (MUÑOZ, 2009, P. 8).

Além disso, apontam para o fato de que, diante da possibilidade de estabelecer outras relações com tal experiência,

[...] muitas pessoas ouvidoras de vozes não se incomodam com elas ou já encontraram suas próprias maneiras de lidar com elas fora da assistência psiquiátrica. (BARROS; SERPA JUNIOR, 2014, P. 567).

Tal como discutido até aqui, o reconhecimento da importância das experiências dos sujeitos e do saber produzido por eles na busca do alívio de seus sofrimentos possibilitaria um diálogo profícuo entre os diferentes protagonistas da reforma psiquiátrica brasileira e uma ampliação da compreensão da mesma.

\section{Considerações finais}

Considerando as análises realizadas durante a pesquisa e as discussões aqui apresentadas, buscou-se argumentar que priorizar a experiência de pessoas acometidas por algum tipo de sofrimento, aflição e/ou perturbação, que buscam os serviços de saúde mental, permite vislumbrar aspectos importantes da reforma psiquiátrica brasileira a serem problematizados, tais como os diferentes saberes produzidos nesse contexto.

Entende-se que tal problematização operaria um deslocamento importante dos sujeitos-usuários/as nas relações estabelecidas nos serviços de saúde mental e permitiria que o conhecimento produzido por eles em suas experiências de adoecimento e tratamento fosse agregado aos demais saberes já instituídos.

Recorreu-se ao conceito de experiência para argumentarmos que a expressão 'experientes' abrange aspectos que se referem às possibilidades abertas pela reorientação da assistência psiquiátrica no Brasil, não contempladas na expressão 'usuário/a'. A ideia também foi demonstrar que existem outras posições a serem conquistadas por tais sujeitos, em suas relações, entendendo que eles fazem muito mais do que apenas 'usar' os serviços de saúde mental. É através das experiências que os conduzem aos serviços, bem como dos 'usos' que fazem dos mesmos, que tais sujeitos se constituem e constituem os serviços.

Entretanto, não se trata de uma mera substituição de uma expressão por outra que pareça mais correta, mas de uma incorporação do saber produzido pelos sujeitos em suas experiências nos serviços de saúde mental. Entende-se que é necessário instituir, no âmbito da política pública de saúde mental, um modo de relação capaz de considerar com seriedade as experiências destas pessoas e, assim, atribuir um estatuto epistemológico ao conhecimento produzido por elas. 


\section{Referências}

AMARANTE, P. D. (Coord.). Loucos pela vida: a trajetória da reforma psiquiátrica no Brasil. Rio de Janeiro: Fiocruz, 1995

BARROS, O. C.; SERPA JUNIOR, O. D. Ouvir vozes: um estudo sobre a troca de experiências em ambiente virtual. Interface, Botucatu, v. 18, n. 50, p. 557-569, jul./ set., 2014.

BASAGLIA, F. Corpo e istituzione. In: BASAGLIA, F. O.; GIANNICHEDDA, M. G. (Org.). L'utopia della realtà. Torino: Piccola Biblioteca Enaudi, 2005. p. 100-113.

BOTT, E. Família e Rede Social. Rio de Janeiro: Francisco Alves, 1976.

BRASIL. Lei n ${ }^{0} 10.216$, de 06 de abril de 2001. Dispõe sobre a proteção e os direitos das pessoas portadoras de transtornos mentais e redireciona o modelo assistencial em saúde mental. Diário Oficial [da] União, Brasília, DF, 9 abr. 2001. Disponível em: <http://www.planalto. gov.br/ccivil_03/leis/leis_2001/110216.htm>. Acesso em: 3 mar. 2017

Lei $n^{\circ} 10.406$, de 10 de janeiro de 2002. Institui o Código Civil. Diário Oficial [da] União, Brasília, DF, 11 jan. 2002. Disponível em: <http://www.planalto.gov.br/ ccivil_03/leis/2002/L10406.htm>. Acesso em: 3 mar. 2017.

Resolução no 433, de 14 de janeiro de 2010. Solicita ao Ministro da Saúde a convocação da IV Conferência Nacional de Saúde Mental, Interministerial, com realização até junho de 2010, objetivando fortalecer o debate da Saúde Mental no SUS. Diário Oficial [da] União, Brasília, DF, 8 fev. 2010. Disponível em: <http://www.in.gov.br>. Acesso em: 3 mar. 2017.

CARDANO, M.; LEPORI, G. Udire la voce degli dei. L'esperienza del gruppo voci. Milano: Franco Angeli, 2012.

CARDOSO, M. R. O.; OLIVEIRA, P. T. R.; PIANI, P.

P. F. Práticas de cuidado em saúde mental na voz dos usuários de um Centro de Atenção Psicossocial do estado do Pará. Saúde em Debate, Rio de Janeiro, v. 40, n. 109, p. 86-99, abr./jun. 2016.

\section{CARTA DE DIREITOS E DEVERES DOS USUÁRIOS} E FAMILIARES DOS SERVIÇOS DE SAÚDE

MENTAL. Santos, 1993. Disponível em: <www.abrasme.org.br/arquivo/download?ID_ARQUIVO=3721>. Acesso em: 16 jun. 2015.

CARVALHO, M. Dilemas na/da Reforma Psiquiátrica: notas etnográficas sobre o cotidiano de um Centro de Atenção Psicossocial. In: FERREIRA, J.; FLEISCHER, S. (Org.). Etnografias em serviços de saúde. Rio de Janeiro: Garamond, 2014. p. 81-105.

CECÍLIO, L. C. C. et al. O agir leigo e o cuidado em saúde: a produção de mapas de cuidado. Cad. Saúde Pública, Rio de Janeiro, v. 30, n. 7, p. 1502-1514, jul. 2014

COLEMAN, R. Lavorare per guarire. Carcare: Magema \& Cooperativa sociale "Il Casello", 2004.

DUARTE, L. F. D. Da vida nervosa nas classes trabalhadoras urbanas. Rio de Janeiro: Jorge Zahar Editor, 1988.

DUARTE, L. F. D. A outra saúde: mental, psicossocial, físicomoral. In: ALVES, P. C.; MINAYO, M. C. S. (Org.). Saúde e doença: um olhar antropológico. Rio de Janeiro: Editora Fiocruz, 1994, p. 83-90.

FOUCAULT, M. História da loucura: na idade clássica. 5 ed. São Paulo: Perspectiva, 1997.

Microfísica do poder. Rio de Janeiro: Graal, 2009.

MALUF, S. W. Gênero, saúde e aflição: políticas públicas, ativismo e experiências sociais. In: MALUF, S. W.; TORNQUIST, C. S. (Org.). Gênero, saúde e aflição: abordagens antropológicas. Florianópolis: Letras Contemporâneas, 2010. p. 21-67.

Além do templo e do texto: desafios e dilemas dos estudos de religião no Brasil. Antropologia em Primeira Mão, Florianópolis, 2011. Disponível em: 
$<$ http://apm.ufsc.br/files/2011/05/124.pdf >. Acesso em: 3 mar. 2017.

MUÑOZ, N. M. Na polifonia de uma orquestra: uma pesquisa clínica com grupos sobre a experiência alucinatória. 2009. Disponível em: <http://www.fundamentalpsychopathology.org/material/coloquio_metodo_clinico/MR/MR01.2.pdf>. Acesso em: 12 fev. 2016.

PELBART, P. P. Manicômio mental: a outra face da clausura. In: LANCETTI, A. (Org.). SaúdeLoucura: Saúde Mental e Saúde da Família. São Paulo: Hucitec, 1990, p. 130-138.

ROMME, M. et al.Vivere con le voci: 50 storie di guarigione. Milano: Mimesis Edizione, 2010.

SCOTT, J. Experiência. In: SILVA, A.; LAGO, M. C. S.; RAMOS, T. R. O. (Org.). Falas de Gênero: teorias, análises, leituras. Florianópolis: Mulheres, 1999. p. 21-55.
SILVEIRA, A. R.; BRANTE, A. R. S. D.; VAN STRALEN, C. J. Práticas discursivas na participação social em saúde mental. Saúde em Debate, Rio de Janeiro, v. 38, n. 103, 783-793, 2014.

TORRE, E. H. G.; AMARANTE, P. D. Protagonismo e subjetividade: a construção coletiva no campo da saúde mental. Ciência \&t Saúde Coletiva, Rio de Janeiro, v. 6, n. 1, p. 73-85, 2001.

WETZEL, C. Avaliação de serviço de saúde mental: a construção de um processo participativo. 2005. $290 \mathrm{f}$. Tese (Doutorado em Enfermagem) - Universidade de São Paulo, Ribeirão Preto, 2005.

Recebido para publicação em outubro de 2016

Versão final em fevereiro de 2017

Conflito de interesses: inexistente

Suporte financeiro: CNPq (Processo no 140752/2011-0) e INCT Brasil Plural 